\title{
Analysis of $\mathrm{G}_{\alpha} \mathbf{4}$, a $\mathrm{G}$-protein subunit required for multicellular development in Dictyostelium
}

\author{
Jeffrey A. Hadwiger and Richard A. Firtel ${ }^{1}$ \\ Department of Biology, Center for Molecular Genetics, University of California, San Diego, La Jolla, \\ California 92093-0634 USA
}

\begin{abstract}
The Dictyostelium $G_{\alpha} 4$ gene encodes a G-protein $\alpha$ subunit that is primarily expressed during the multicellular stages of development. $g_{\alpha} 4$ null mutants, created by gene disruption, show aberrant morphological differentiation, reduced levels of prespore gene expression, and a loss of the ability to produce spores. These developmental phenotypes can be rescued by complementation with the wild-type gene. Cells that overexpress the $G_{\alpha} 4$ gene $\left(G_{\alpha} 4^{H C}\right)$ also show reduced spore production but display an aberrant morphological phenotype distinct from that of $g_{\alpha} 4$ cells. The $g_{\alpha} 4$ phenotype can be partially rescued by the presence of wild-type or $G_{\alpha} 4^{H C}$ cells in chimeric organisms, suggesting that $G_{\alpha} 4$-expressing cells produce an intercellular signal that is essential for multicellular development.
\end{abstract}

[Key Words: G protein; signal transduction; Dictyostelium]

Received September 18, 1991; revised version accepted November 11, 1991.

Understanding the molecular mechanism by which cells receive and process signals from their environment is the focus of many research efforts. Cells are continually responding to environmental signals that may be sent from other cells (hormones, neurotransmitters, chemoattractants, etc.) or from noncellular origins (nutrients, light, temperature, odors, etc.); and in many cases, the responses involve specific gene regulation, metabolic adjustments, cell differentiation, cell division, and/or cell migration. The mechanisms of cellular response often involve regulatory components such as heterotrimeric $G$ proteins that transduce signals from cell-surface receptors to intracellular effectors (for reviews, see Gilman 1987; Neer and Clapham 1988; Johnson and Dhanasekaran 1989; Simon et al. 1991). These G proteins are heterotrimeric, composed of $\alpha, \beta$, and $\gamma$ subunits, in which the $\alpha$ subunit can bind and hydrolyze guanine nucleotides. A general model for G-protein activation involves a receptor-catalyzed exchange of GDP associated with the $\alpha$ subunit for GTP, which then allows the $\alpha$ subunit to dissociate from the $\beta \gamma$ subunits and stimulate its downstream effector. Recently, there has been a substantial increase in the number of newly identified $\alpha$ subunits in a variety of organisms; however, at present, little is known about the signal transduction pathways in which they operate (Strathmann et al. 1989; Strathmann and Simon 1990).

Signal transduction pathways mediated by $\mathrm{G}$ proteins have been shown or implicated to be important for many

${ }^{1}$ Corresponding author. cell-cell communication processes including the aggregation phase of Dictyostelium development (for reviews, see Williams 1988; Devreotes 1989; Firtel et al. 1989). Dictyostelium has a relatively simple and rapid developmental life cycle that consists of the aggregation of $\sim 10^{5}$ individual amebae to form a multicellular mound that differentiates into a migrating slug and eventually culminates to form a fruiting body in $\sim 24 \mathrm{hr}$ (Loomis 1982). Because Dictyostelium wild-type cells are haploid, one is able to use genetic and biochemical analyses to examine recessive mutants that are perturbed in developmental functions. Previous analysis of the Dictyostelium $G_{\alpha} 2$ gene indicates that the encoded subunit is required for the aggregation phase of development. Analysis of $G_{\alpha} 2$ deletion mutations, including those resulting from gene disruptions, shows that $g_{\alpha} 2$ cells do not aggregate and lack all known cAMP receptor-mediated responses, such as stimulation of adenylyl cyclase, guanylyl cyclase, phospholipase $\mathrm{C}$ activity, developmental gene expression, and chemotaxis to cAMP, except for cAMP-mediated $\mathrm{Ca}^{2+}$ influx (Kesbeke et al. 1988, 1990; Kumagai et al. 1989a,b, 1991; Milne and Coukell 1991).

Two other $\mathrm{G}_{\alpha}$ genes, $G_{\alpha} 4$ and $G_{\alpha} 5$, have recently been identified that are primarily expressed late in development and, therefore, might be associated with signal transduction pathways involved in cell-type differentiation, pattern formation, or a number of morphological changes in the multicellular organism (Hadwiger et al. 1991). The $G_{\alpha} 4$ gene is also expressed at a low level during growth and early development. At the mound stage, levels of $G_{\alpha} 4$ mRNA increase substantially and remain 
high throughout the rest of development. The entire coding region of the $G_{\alpha} 4$ gene has been sequenced and encodes a $G_{\alpha}$ subunit that contains some unusual sequence divergences within the highly conserved domains that are known to interact with guanine nucleotides (Hadwiger et al. 1991). The deviations suggest that $\mathrm{G}_{\alpha} 4$ might represent a member of a new class of $G_{\alpha}$ subunits that have altered interaction with guanine nucleotides in comparison to mammalian $\mathrm{G}_{\alpha}$ s or $\mathrm{G}_{\alpha} \mathrm{i}$ subunits.

This report describes the analysis of $G_{\alpha} 4$ gene function during development by examining the phenotypes of $g_{\alpha} 4$ null mutants or cells that overexpress the $G_{\alpha} 4$ gene. These analyses suggest that cells expressing the $G_{\alpha} 4$ gene play a key regulatory role that influences the morphology and gene expression of the entire multicellular organism through an intercellular signal.

\section{Results}

Creation of a $\mathrm{g}_{\alpha} 4$ null mutant

To determine whether $G_{\alpha} 4$ function is essential for proper development, a $g_{\alpha} 4$ null mutant was created by gene disruption using an auxotrophic marker selection similar to that described previously for the analysis of the Dictyostelium $G_{\alpha} 1$ and $G_{\alpha} 2$ genes (Kumagai et al. 1991). The auxotrophic marker used was the Dictyostelium PYR5-6 gene [encodes UMP-synthase (Boy-Marcotte et al. 1984/l, which is required for the synthesis of uracil and confers sensitivity of Dictyostelium cells to the growth-inhibiting drug 5-fluoro-orotic acid (5-FOA) (Kalpaxis et al. 1990). A uracil auxotroph, strain JH8 (isogenic to KAx-3 wild-type cells except for the PYR5-6 locus), was created and transformed with a $g_{\alpha} 4:: P Y R 5-6$ gene disruption construct (see Materials and methods and Fig. 1). Transformants were selected in FM minimal medium (Franke and Kessin 1977) and plated on nutrient agar plates carrying a lawn of Klebsiella aerogenes for clonal plaque selection and preliminary analysis of developmental phenotypes (see Materials and methods). Approximately $10-20 \%$ of the cloned transformants displayed an extreme defect in developmental morphology, as well as a slow plaque growth rate on lawns of bacteria (data not shown). DNA blot analysis of mutant and wildtype clones indicated a direct correlation between the mutant phenotypes and the disruption of the $G_{\alpha} 4$ locus by the insertion of the PYR5-6 gene (data not shown; see Materials and methods). One of these clones, designated as strain JH142 (genotype $g_{\alpha} 4:: P Y R 5-6$ ), was used for all subsequent analyses.

Developmental morphology of the $g_{\alpha} 4$ cells was analyzed further by plating axenically grown cells washed free of medium on non-nutrient agar plates. The $g_{\alpha} 4$ cells aggregate to form mounds that differentiate into an erect finger morphology (Fig. 2B) similar to wild-type cells (Fig. 2A). In contrast to wild-type development in which the finger drops to the substratum as a migrating slug, the $g_{\alpha} 4$ finger continues to elongate. The final developmental morphology of $g_{\alpha} 4$ cells results in a mound of cells with a distorted upward extension that is often
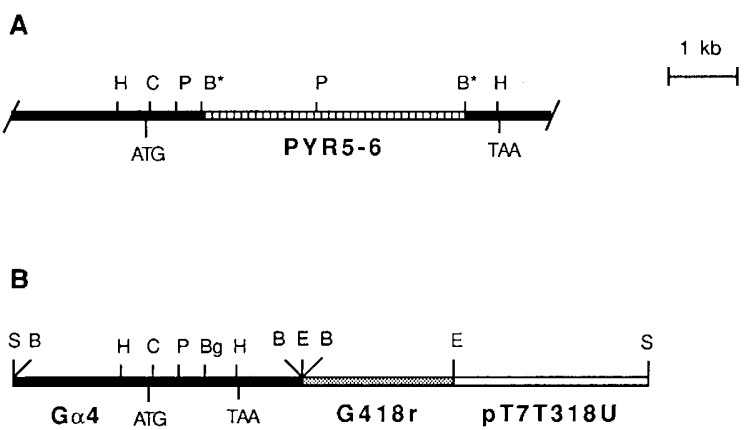

C

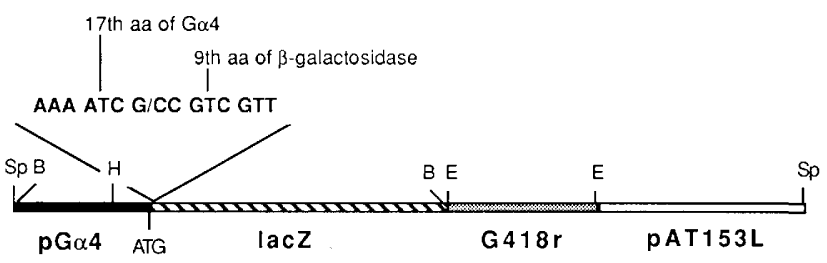

Figure 1. $G_{\alpha} 4$ gene constructs. (A) Map of $g_{\alpha} 4:: P Y R 5-6$ gene disruption. A $3.7-\mathrm{kb}$ fragment containing the wild-type PYR5-6 gene was inserted into the $B g l I I$ site of a cloned $G_{\alpha} 4$ genomic fragment. The resulting $g_{\alpha} 4:: P Y R 5-6$ construct was digested with HindIII and ClaI, excising a fragment containing the PYR5-6 gene flanked by $G_{\alpha} 4$-coding sequences and then transformed into the strain JH8. Disruption of the $g_{\alpha} 4$ locus in the strain JH142 was confirmed by DNA blot analysis probing a $B g$ III-HindIII fragment internal to the $G_{\alpha} 4$ open reading frame. Only a 5-kb HindIII fragment and a $2.2-\mathrm{kb}$ PvuII-HindIII fragment were detected from the JH142 cells, compared with a 2.0 $\mathrm{kb}$ HindIII fragment and a $0.8-\mathrm{kb}$ PvuII-HindIII fragment from wild-type cells. This is consistent with a replacement of the wild-type gene with the mutant allele. $(B)$ Map of $G_{\alpha} 4$ expression vector $\mathrm{pJH154}$ (C) Map of $p G_{\alpha} 4:: 1 a c \mathrm{Z}$ gene fusion vector pJH161. $G_{\alpha} 4$ genomic sequences are represented by solid segments. A detailed description of the construction of the expression vectors is presented in Materials and methods. (G418 $)$ The pACT6::NeO ${ }^{r}$ gene fusion that confers resistance to the drug G418: (ATG and TAA) the initiation and termination codons respectively, of the $G_{\alpha} 4$ gene. Restriction enzyme sites are shown: BamHI (B), BglII (Bg), BgIII-BamHI fusion (B*), ClaI (C), EcoRI (E), HindIII (H), PvaII (P), SalI (S), and SphI (Sp).

twisted up on itself (Fig. 2D,E). The development of $g_{\alpha} 4$ cells does not result in any slug stage or fruiting body formation as seen with wild-type cells (Fig. 2C). Only $\sim 0.02 \%$ of $g_{\alpha} 4$ cells plated for development differentiate to form viable spores, as determined by resistance to detergent or heat treatment, in contrast to $\sim 85 \%$ for wildtype cells (see Materials and methods and Table 1).

To confirm that the aberrant development observed for $g_{\alpha} 4$ cells is due only to the loss of the $G_{\alpha} 4$ gene, the vector pJH154 (Fig. 1B) containing the wild-type $G_{\alpha} 4$ genomic sequence was transformed into $g_{\alpha} 4$ cells to complement the $g_{\alpha} 4:: P Y R 5-6$ mutation. Transformants that contained a low copy number $(\sim 1-10$ copies by DNA blot analysis; data not shown) of this vector display nor- 


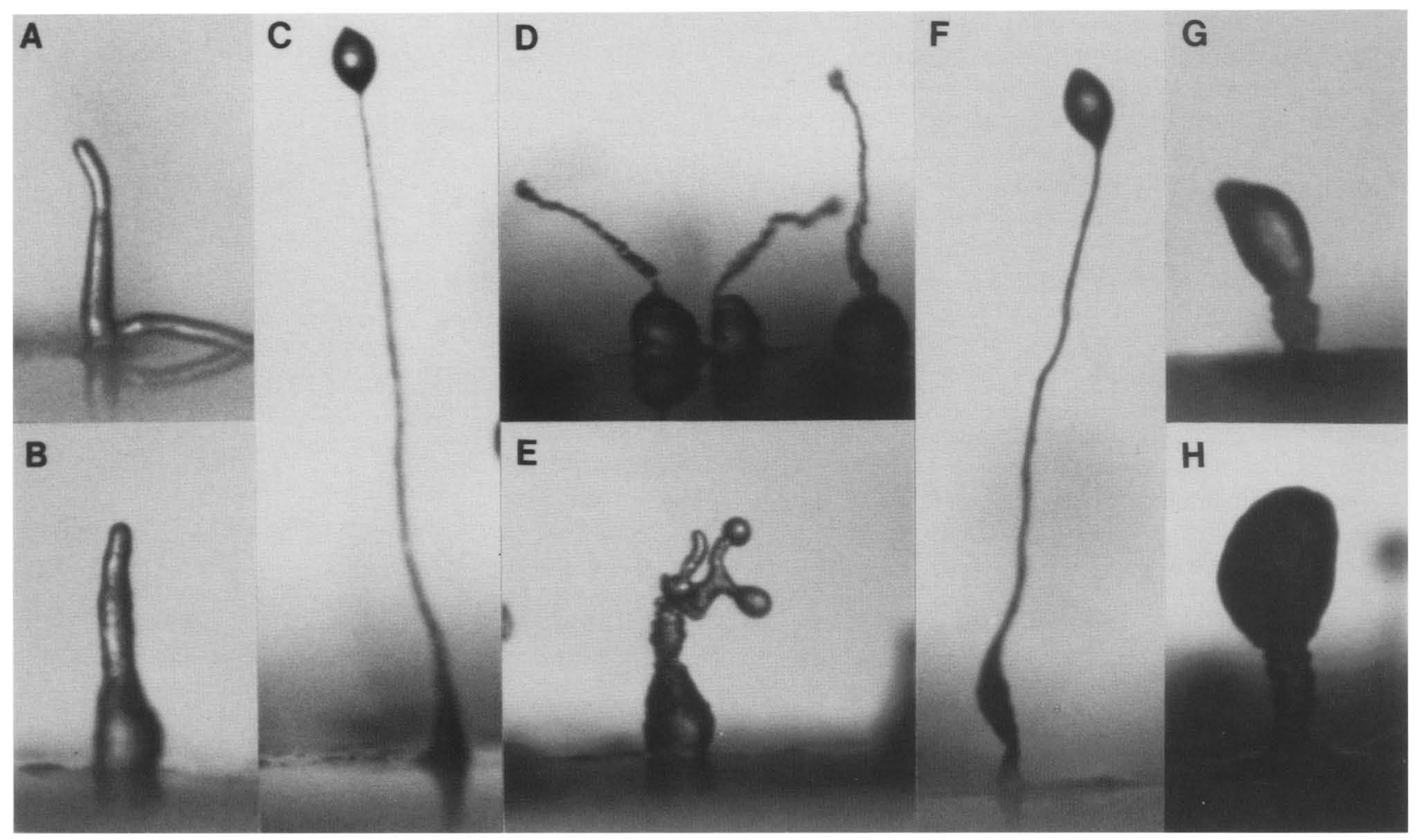

Figure 2. Developmental morphology of $g_{\alpha} 4, G_{\alpha} 4^{H C}$, and wild-type cells. Cells were grown axenically and plated on non-nutrient plates for development as described in Materials and methods. $(A)$ Wild-type cells at finger stage $\left(14 \mathrm{hr}\right.$ after starvation); $(B) g_{\alpha} 4$ cells at finger stage $(15 \mathrm{hr}$ after starvation); $(C)$ wild-type cells at fruiting body stage $(>26 \mathrm{hr}$ after starvation; photo taken at $36 \mathrm{hr}) ;(D, E)$ $g_{\alpha} 4$ cells at final morphological stage (photo taken $36 \mathrm{hr}$ after starvation); $(F) g_{\alpha} 4$ cells complemented with low copy number of $G_{\alpha} 4$ expression vector at fruiting body stage (photo taken $36 \mathrm{hr}$ after starvation); $(G, H) G_{\alpha} 4^{H C}$ cells at final morphological stage (photo taken $36 \mathrm{hr}$ after starvation).

mal plaque growth rate on bacterial lawns and developmental morphology identical to wild-type cells (Fig. 2F), suggesting that the $G_{\alpha} 4$ gene disruption is responsible for all developmental aberrations observed in $g_{\alpha} 4$ cells. However, $g_{\alpha} 4$ or wild-type cells containing a high copy number (ca. $>20$ tandomly repeated copies by DNA blot analysis) of the $G_{\alpha} 4$ vector display an aberrant developmental morphology, indicating that overexpression of the $G_{\alpha} 4$ gene is detrimental to proper development. In addition, these high-copy-number transformants also display an unusually fast plaque growth rate on bacterial lawns. A clonal isolate of wild-type cells containing a high copy number of the $G_{\alpha} 4$ vector was designated as strain $\mathrm{JH} 182$ (genotype $G_{\alpha} 4^{H C}$ in which $H C$ represents high copy) and used for further analysis.

When $G_{\alpha} 4^{H C}$ cells are grown axenically and developed on non-nutrient agar plates, the cells aggregate at the same rate as wild-type cells, but the initial "loose"

Table 1. Spore production in $\mathrm{G}_{\alpha} 4$ mutants and chimeric organisms

\begin{tabular}{lcccccc}
\hline & \multicolumn{5}{c}{ Percent spore production in strains ${ }^{\mathrm{a}}$} \\
\cline { 2 - 7 } Spores & WT & $g_{\alpha} 4$ & $G_{\alpha} 4^{H C}$ & WT $\times g_{\alpha} 4$ & $g_{\alpha} 4 \times G_{\alpha} 4^{H C}$ & WT $\times G_{\alpha} 4^{H C}$ \\
\hline WT & $100 \pm 8 \%$ & - & - & $77 \pm 6 \%$ & - & $104 \pm 6 \%$ \\
$g_{\alpha} 4$ & - & $0.02 \pm 0.01 \%$ & - & $3 \pm 1 \%$ & $2 \pm 1 \%$ & $-11 \pm 8 \%$ \\
$G_{\alpha} 4^{H C}$ & - & - & $4 \pm 2 \%$ & - & $88 \pm 5 \%$ \\
\hline
\end{tabular}

a Percentage of input cells that form viable spores, as determined by resistance to heat treatment (see Materials and methods), $48 \mathrm{hr}$ after the onset of development [e.g., in the wild-type (WT) $\times g_{\alpha} 4$ chimera, $77 \%$ of the wild-type cells form spores and $3 \%$ of the $g_{\alpha} 4$ cells form spores]. Percentages are normalized to a $100 \%$ wild-type spore production (generally $85 \%$ of input cells form spores in wild-type strain). Data for spore production, determined by resistance to detergent, is not shown but is very similar to that shown here. Results are presented as the mean of four separate experiments in which spore production was determined in duplicate. Error is presented as S.E.M. 
mounds disperse to form a ring of cells that later regroup to form one or more mounds. This phenomenon, which occurs occasionally with wild-type cells, is a very prominent phase of $G_{\alpha} 4^{H C}$ development. The $G_{\alpha} 4^{H C}$ cells do not form "tight" mounds until $18 \mathrm{hr}$, whereas wild-type cells start to form tight mounds at $9 \mathrm{hr}$ after starvation. Many of the $G_{\alpha} 4^{H C}$ mounds differentiate at $24-36 \mathrm{hr}$ to form club-like structures consisting of an irregular mass of cells on top of a short, thick stalk (Fig. 2G,H). During this period, a low percentage of $G_{\alpha} 4^{H C}$ mounds $(<10 \%)$ differentiate to form small "fruiting body-like" structures, which are not observed when $G_{\alpha} 4^{H C}$ cells are grown and developed on nutrient agar plates with bacteria. These fruiting body-like structures are not observed in all $G_{\alpha} 4^{H C}$ strains, suggesting that their development might depend on the relative levels of the $G_{\alpha} 4$ gene. The $G_{\alpha} 4^{H C}$ cells do not form migrating slugs, and on average, $\sim 4 \%$ of the developing cells differentiate to form viable spores (see Table 1). The ability of the $G_{\alpha} 4^{H C}$ strains to produce spores also varies among the different clonal isolates and may also depend on the copy number of the $G_{\alpha} 4$ gene.

\section{Regulation of prespore and prestalk gene expression} in $\mathrm{g}_{\alpha} 4$ and $\mathrm{G}_{\alpha}{ }^{\mathrm{HC}}$ mutants

The developmental morphology of $g_{\alpha} 4$ cells appears to deviate from that of wild-type cells after mound formation, the stage at which the spatial patterning of prestalk and prespore cells is defined, as has been observed previously by expressing the Escherichia coli lacZ gene from prestalk- or prespore-specific promoters /Williams et al. 1989; Haberstroh and Firtel 1990; Esch and Firtel 1991|. Prespore gene expression, as defined by the $S P 60$ promoter, is localized to the central region of the tipped mound that eventually comprises the majority of the posterior $\sim 85 \%$ of the slug (Fig. 3A) before forming the sorocarp (spore mass) of the mature fruiting body. The spatial pattern of prespore gene (pSP60::lacZ) expression in $g_{\alpha} 4$ mounds resembles that in wild-type mounds (data not shown). The lacZ-expressing cells remain localized in the mound as the tip extension continues to elongate throughout the final stages of $g_{\alpha} 4$ development (Fig. 3C). In all $g_{\alpha} 4$ transformants, the relative level of $p S P 60:: 1 a c Z$ expression is lower than that observed in wild-type transformants. In wild-type cells, prestalk gene expression, as defined by the Ddras $D$ promoter, is primarily localized in the anterior $\sim 15 \%$ and very posterior $\sim 3 \%$ of migrating slugs. In addition, a small number of DdrasD-expressing cells are also scattered throughout the prespore region (anterior-like cells) (Fig. 3B; Esch and Firtel 1991) (note: Ddras D was previously called $D d r a s$.$) .$ These $D d r a s D$-expressing prestalk cells eventually form the very apical tip, basal disk, and stalk of the fruiting body. Prestalk gene ( $p D d r a s D:: 1 a c Z$ ) expression in $g_{\alpha} 4$ cells is primarily localized to the tip of the mound, with a lower level of expression scattered throughout the mound, similar to that observed in wild-type mounds. As development proceeds, the overall pattern of prestalk expression does not change (Fig. 3D), suggesting that $g_{\alpha} 4$ morphogenesis does not proceed much past the finger stage. Differences in the spatial pattern of prestalk gene expression in the $g_{\alpha} 4$ mutant compared to wild-type cells, like those observed for prespore expression, appear

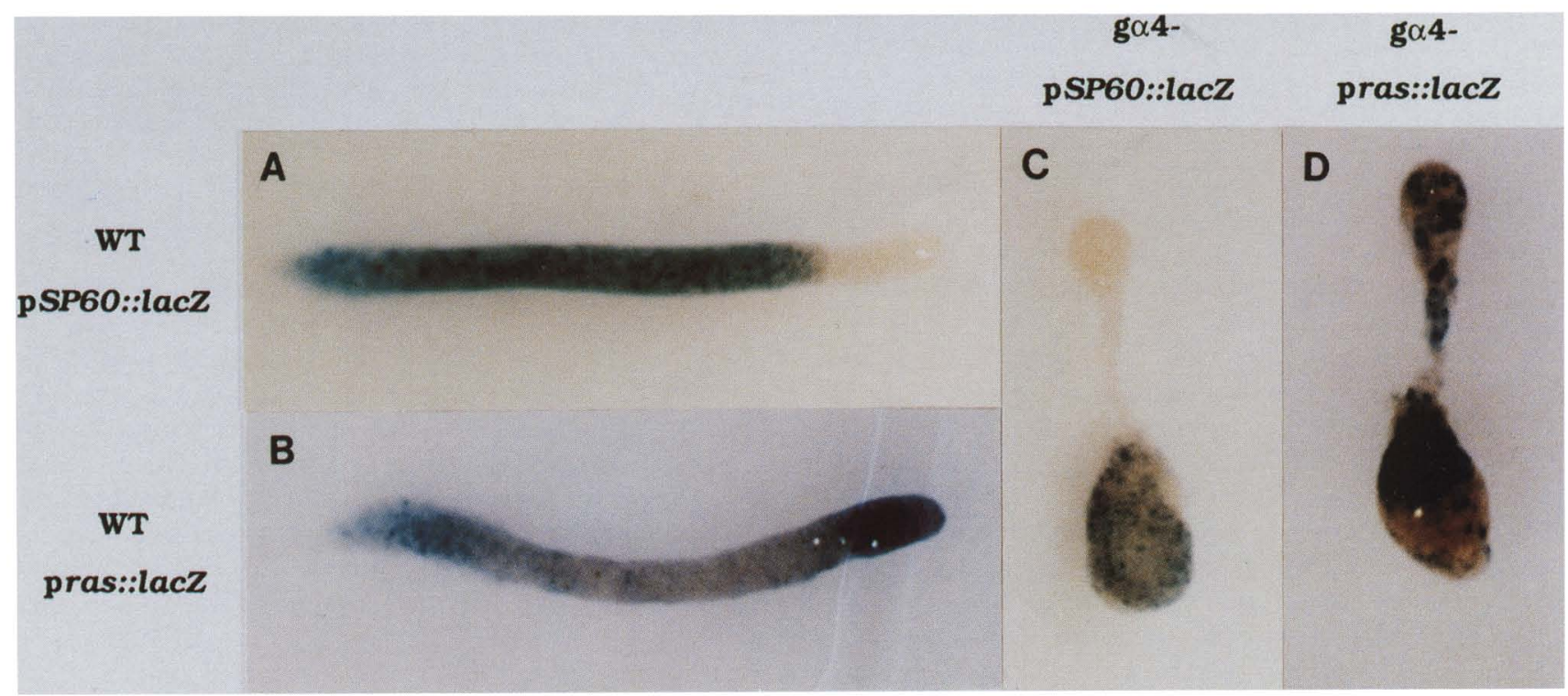

Figure 3. Cytological staining of $p S P 60:: 1 a c Z$ and $p D d r a s D:: 1 a c Z$ constructs in wild-type and $g_{\alpha} 4$ cells. Development and staining procedures are described in Materials and methods. (A) Wild-type cells carrying $p$ SP0::lac Z gene fusion at $16 \mathrm{hr}$ of development; $(B)$ wild-type cells carrying $p D d r a s D:: 1 a c Z$ gene fusion at $16 \mathrm{hr}$ of development; $(C)$ clonal $g_{\alpha} 4$ cells carrying the $p S P 60:: 1 a c Z$ gene fusion at $16 \mathrm{hr}$ of development; $(D)$ clonal $g_{\alpha} 4$ cells carrying the $p D d r a s D:: 1 a c Z$ gene fusion at $16 \mathrm{hr}$ of development. The staining patterns of $l a c Z$ gene fusion constructs in $g_{\alpha} 4$ cells were identical in multiple clones and in populations of transformants. 
later in development when the overall morphology of $g_{\alpha} 4$ development deviates from that of wild-type cells.

The lack of proper spore production and relatively poor expression of the $p S P 60:: 1 a c Z$ gene in $g_{\alpha} 4$ cells suggest that the levels of prespore gene expression might be lower than those in wild-type development. To examine prespore and prestalk gene expression in $g_{\alpha} 4$ cells, RNA was isolated at various times during development and analyzed for the levels of transcripts from two prespore genes (SP60 and 14-E6), a prestalk gene (DdrasD), and a prestalk-enriched gene (pst-cath/CP2) (Mehdy et al. 1983; Reymond et al. 1984; Pears et al. 1985; Datta et al. 1986; Saxe and Firtel 1986; Haberstroh and Firtel 1990). The expression level of both prespore genes is severely reduced and is temporally delayed in $g_{\alpha} 4$ cells compared with expression levels observed in wild-type cells [Fig. 4A, upper panel (data for 14-E6 expression is not shown)]. Expression of the DdrasD and pst-cath/CP2 genes is reduced only slightly in the $g_{\alpha} 4$ cells and appears to show the normal temporal patterns of induction [Fig. 4A, lower panel (data for pst-cath/CP2 is not shown)].

The apparent delay of $G_{\alpha} 4^{H C}$ cells in forming tight mounds and the low efficiency of these cells in forming viable spores suggest that the high copy number of the $G_{\alpha} 4$ gene in these cells might also affect the levels of prespore and prestalk gene expression. RNA blot analysis of developing $G_{\alpha} 4^{H C}$ cells indicates a severe delay in both prespore (SP6O) and prestalk (DdrasD) gene expression (Fig. 4B, upper and middle panels). High levels of $S P 60$ and DdrasD transcripts are not observed until between 18 and $24 \mathrm{hr}$ into development, consistent with the delay of tight mound formation of $G_{\alpha} 4^{H C}$ cells until this time. Expression of the prestalk-enriched gene pstcath/CP2 is also delayed in $G_{\alpha} 4^{H C}$ but is fully induced by $18 \mathrm{hr}$ in contrast to $24 \mathrm{hr}$ for DdrasD (data not shown).

The level of $G_{\alpha} 4$ expression was also analyzed in the $G_{\alpha} 4^{H C}$ cells and, as expected, found to be greatly increased over that of wild-type levels at all stages of development (Fig. 4B, bottom panel). The developmental induction of $G_{\alpha} 4$ expression in $G_{\alpha} 4^{H C}$ cells appears to peak slightly later in development than in wild-type cells. It is not known whether this later peak of $G_{\alpha} 4$ expression is a result of the delay in morphogenesis or a change in $G_{\alpha} 4$ mRNA stability. The extremely high levels of $G_{\alpha} 4$ transcripts in $G_{\alpha} 4^{H C}$ cells suggest that the aberrant developmental phenotype is the result of the overexpression of the $G_{\alpha} 4$ subunit. The apparent sizes of the overproduced $G_{\alpha} 4$ transcripts appear to be similar to those observed in wild-type cells, suggesting that transcriptional initiation and termination sites have been conserved in the $G_{\alpha} 4$ expression construct. The increased levels of $G_{\alpha} 4$ expression are not completely proportional at all stages of development with the expression of $G_{\alpha} 4$ in wild-type cells, suggesting that the $G_{\alpha} 4^{H C}$ phenotype influences $G_{\alpha} 4$ expression. This effect may result from alterations in the percentage of cells that express the $G_{\alpha} 4$ gene and/or from alterations in the level of $G_{\alpha} 4$ expression in any given cell.

The expression of some developmental genes can be induced by cAMP in shaking cultures of starved cells,
A
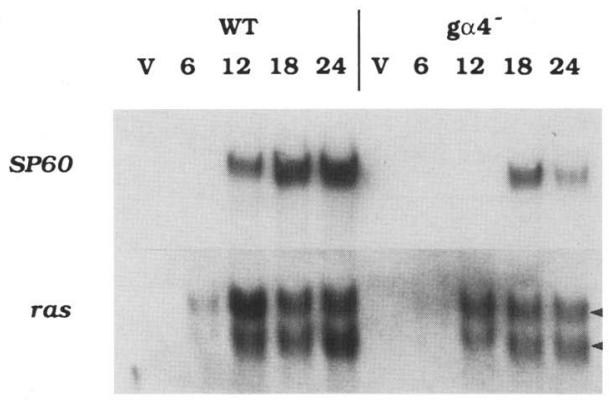

B

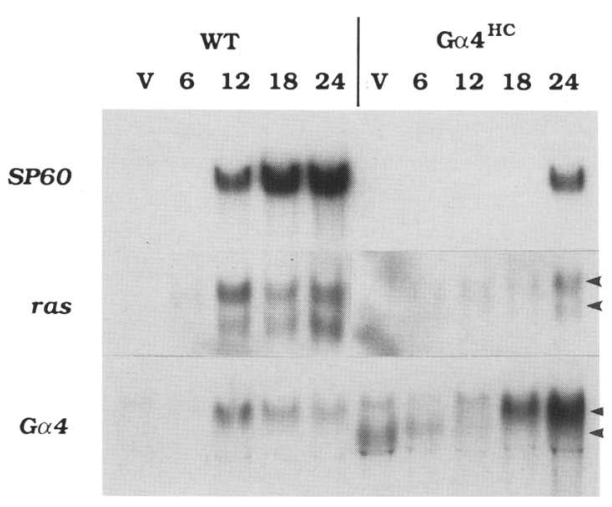

Figure 4. Developmental expression of SP60 (prespore), DdrasD (prestalk), and $G_{\alpha} 4$ genes in $g_{\alpha} 4, G_{\alpha} 4^{H C}$, and wild-type cells. Total RNA was isolated from cells at times indicated. (V) Vegetatively growing cells were size-fractionated on denaturing gels, blotted, and hybridized with $S P 60, D d r a s D$, or $G_{\alpha} 4$ probes as described previously (Mann and Firtel 1987). (A) SP60 and $D$ dras $D$ gene expression in wild-type and $g_{\alpha} 4$ cells. Arrowheads indicate the two $D d r a s D$ transcripts. These gels do not separate the transcripts from the middle and proximal promoters, and these transcripts run together as the lower band seen in the blot (see Esch and Firtel 1991). (B) SP60, DdrasD, and $G_{\alpha} 4$ gene expression in wild-type and $G_{\alpha} \alpha^{H C}$ cells. Dark areas in lanes $V$ and 6 of DdrasD expression in $G_{\alpha}{ }^{H C}$ cells are not bands. The $D d r a s D$ transcripts are indicated by arrowheads. Two $G_{\alpha} 4$ transcripts are seen in the $G_{\alpha} 4^{H C}$ lanes and are indicated by arrowheads. The lower transcript is also seen in wild-type cells upon longer exposure.

conditions in which no morphological differentiation occurs (Mehdy et al. 1983; Mehdy and Firtel 1985). The induction of Ddras $D$ expression is reduced severely in shaking cultures of $g_{\alpha} 4$ cells compared with that observed for wild-type cells (data not shown). Under these conditions, there are no extended cell-cell contacts, and presumably, the concentrations of extracellular factors are low except for the exogenously added cAMP, implying that gene regulation is cell autonomous. Therefore, the subset of cells that express the DdrasD gene (Esch and Firtel 1991) may also express the $G_{\alpha} 4$ gene. The induction of a prestalk-enriched gene, pst-cath/CP2, in shaking cultures of $g_{\alpha} 4$ cells was identical to that of wild-type cells, suggesting that $G_{\alpha} 4$ function is not required for the proper induction all cAMP-induced genes in shaking cultures (data not shown). 
The expression of the $G_{\alpha} 4$ gene was also examined in shaking cultures of wild-type, $g_{\alpha} 4$, and $G_{\alpha} 4^{H C}$ cells. The $G_{\alpha} 4$ gene was induced in cAMP-treated shaking cultures of wild-type and $G_{\alpha} 4^{H C}$ cells (data not shown), indicating that the $G_{\alpha} 4$ expression is induced by cAMP under conditions similar to those required by some prestalk genes (e.g., DdrasD), prestalk-enriched genes (e.g., pst-cath/ $C P 2$ ), and non-cell-type-specific, cAMP-inducible genes (e.g., CP1) (Mehdy et al. 1983; Reymond et al. 1984; Mehdy and Firtel 1985; Pears et al. 1985; Datta et al. 1986; Saxe and Firtel 1986; Jermyn et al. 1987).

\section{Spatial expression of the $\mathrm{G}_{\alpha} 4$ gene}

To better understand the role of $G_{\alpha} 4$ function during development, the spatial pattern of $G_{\alpha} 4$ expression was examined using a $p G_{\alpha} 4:: 1 a c Z$ gene fusion that contains the functional $G_{\alpha} 4$ promoter, as determined by complementation analysis of $g_{\alpha} 4$ cells (see vector pJH161; Fig.
1C). This vector, containing the $p G_{\alpha} 4:: 1 a c Z$ gene fusion and a gene fusion conferring G418 resistance, was transformed into wild-type and $g_{\alpha} 4$ cells. Clonal populations of wild-type cells carrying this $p G_{\alpha} 4:: 1 a c Z$ gene fusion display $\beta$-galactosidase activity in a small subset of cells that were distributed over the entire organism at all stages of multicellular development, although the expression of $\beta$-galactosidase appears to be slightly greater in some regions (Fig. 5). This is particularly evident in the posterior part of the slug and in the caps of cells on the top and bottom of the spore mass of the fruiting body. These cells are thought to be derived from prestalk and/or anterior-like cells (Sternfeld and David 1982; Esch and Firtel 1991; Jermyn and Williams 1991). Many of these cells that prominently express the $p G_{\alpha} 4: \because 1 a c Z$ fusion gene also appear to be located near or on the outer surface of the multicellular organism. This pattern is not likely to be a staining artifact, as the staining protocol used for this analysis also identifies $\beta$-galactosidase-ex-

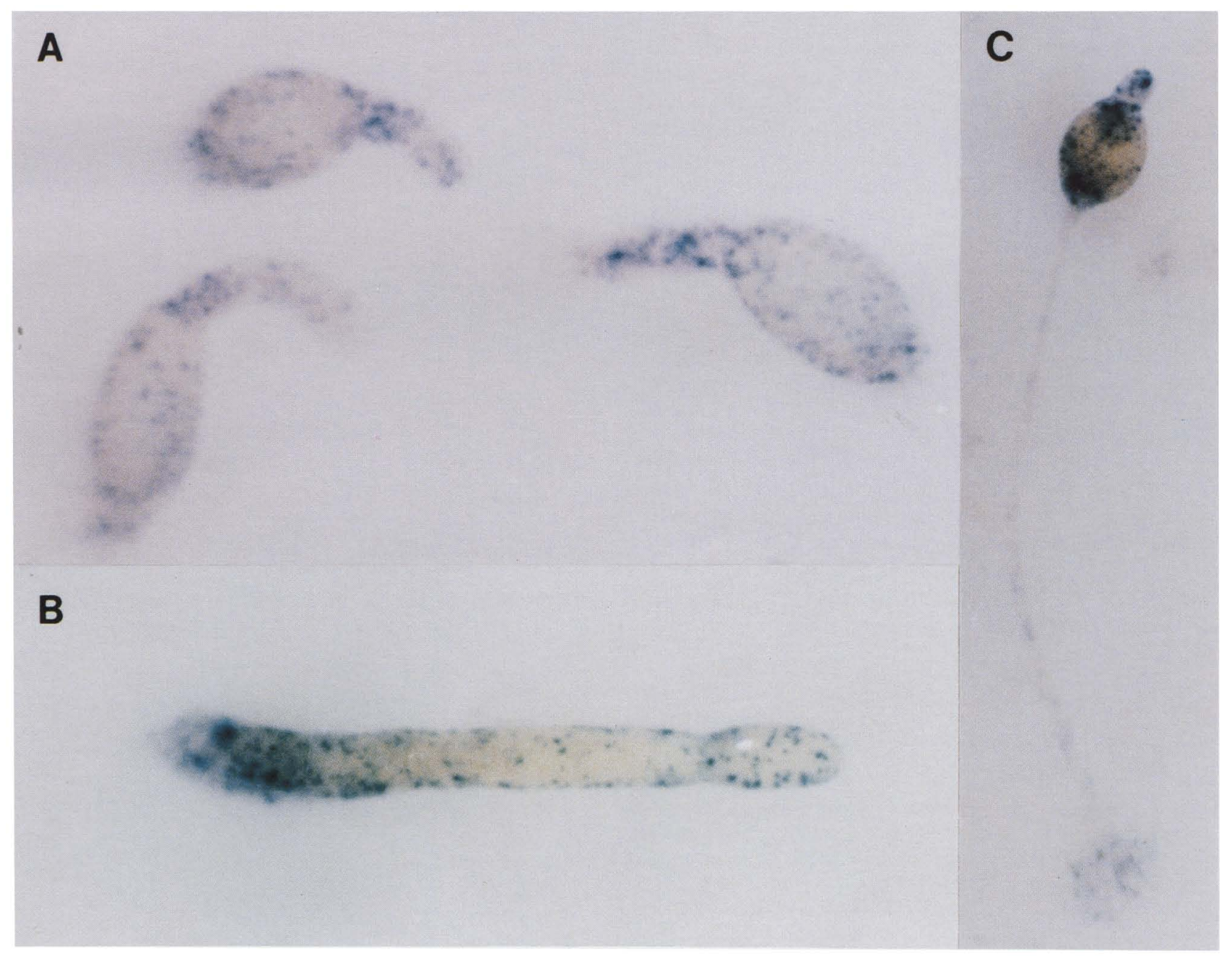

Figure 5. Cytological staining of $p G_{\alpha} 4: 1 a c Z$ constructs in clonal wild-type transformants during development. Development and staining procedures are described in Materials and methods. The staining pattern was similar in 10 clones examined for the expression of $p G_{\alpha} 4:: 1 a c Z$ gene fusion. $(A)$ Tipped mound stage $(13 \mathrm{hr}$ of development $) ;(B)$ migrating slug stage $(16 \mathrm{hr}$ of development $) ;(C)$ fruiting body stage ( $24 \mathrm{hr}$ of development). 
pressing cells located internally within the slug using other constructs (see Fig. 3). It is possible that additional cells within the aggregate also express the $G_{\alpha} 4$ gene, but at a level too low to be seen with this assay. A similar spatial organization of the $p G_{\alpha} 4:: 1 a c Z$-expressing cells was seen in $g_{\alpha} 4$ mounds (data not shown), suggesting that $G_{\alpha} 4$ function is not essential for $G_{\alpha} 4$ gene expression or to establish this spatial pattern of expression. However, quantitative differences in levels of expression might not be detected by this technique.

\section{Presence of wild-type or $\mathrm{G}_{\alpha} 4^{\mathrm{HC}}$ cells can partially rescue the $\mathrm{g}_{\alpha} 4$ phenotype}

As described above, only a small subset of cells prominently express the $G_{\alpha} 4$ gene at any given time during development, although $\mathrm{G}_{\alpha} 4$ function appears to affect gene expression in the majority of developing cells. It is possible that a low level of $G_{\alpha} 4$ gene expression, undetectable by the analysis of the $p G_{\alpha} 4 \because 1 a c Z$ gene fusion, is sufficient to provide this function or that cells prominently expressing the $G_{\alpha} 4$ gene may produce an intercellular signal required for proper developmental gene expression and subsequent morphogenesis. In the latter case, the presence of such a signal from wild-type cells might facilitate the ability of $g_{\alpha} 4$ cells to undergo proper development.

To determine whether $g_{\alpha} 4$ cells are capable of synergizing with wild-type cells, chimeric organisms were created by mixing an equal number of $g_{\alpha} 4$ and wild-type cells and allowing them to undergo development. The mixed population of cells developed similarly, both temporally and morphologically, to homogeneous wild-type populations of cells (Fig. 6A-C), suggesting that the presence of wild-type cells can rescue the $g_{\alpha} 4$ morphology or that the wild-type and $g_{\alpha} 4$ cells are being segregated during development. To examine the spatial distribution of $g_{\alpha} 4$ and wild-type cells in the chimeric organisms, wildtype and $g_{\alpha} 4$ cells were transformed with a $p A C T 6:: 1 a c Z$ gene fusion (for vector construction, see Materials and methods) that expresses $\beta$-galactosidase activity in all cell types and during all stages of development (Dingermann et al. 1989). Clonal populations of wild-type cells carrying the $p A C T 6:: 1 a c Z$ gene fusion were mixed with nontransformed $g_{\alpha} 4$ cells, and, conversely, populations of $g_{\alpha} 4$ cells carrying the $p A C T 6:: 1 a c Z$ gene fusion were mixed with nontransformed wild-type cells. The spatial distribution of $g_{\alpha} 4$ cells expressing $\beta$-galactosidase activity appeared to be evenly mixed with wild-type cells throughout the slug stage (data not shown). During culmination, $g_{\alpha} 4$ cells are found throughout the entire fruiting body. However, a large proportion of $g_{\alpha} 4$ cells, based on the spatial pattern of $\beta$-galactosidase activity in the $g_{\alpha} 4(p A C T 6:: 1 a c Z) \times$ wild-type chimera, appeared to reside in the lower stalk region (Fig. 7A). This partial segregation during culmination was confirmed by the converse chimera, wild-type $(p A C T 6:: 1 a c Z) \times g_{\alpha} 4$ (Fig. 7B). The chimeras were analyzed for the percentage of wildtype and $g_{\alpha} 4$ cells producing mature spores. The results show that the percentage of $g_{\alpha} 4$ cells that form viable spores is greatly increased (Table 1), even though there appears to be partial segregation of wild-type and $g_{\alpha} 4$ null cells in the chimeric fruiting body. These data suggest that the wild-type cells are providing some intercellular signal that partially rescues the $g_{\alpha} 4$ phenotype.

$G_{\alpha} 4^{H \mathrm{C}}$ cells were also analyzed for the ability to synergize with $g_{\alpha} 4$ and wild-type cells. Both $g_{\alpha} 4$ and $G_{\alpha} 4^{H C}$ cells produce very distinct, aberrant morphologies when developed alone; however, chimeras containing an equal mixture of cells of both mutants result in temporal and morphological development similar to that of wild-type cells (Fig. 6C-E). This mixture also results in a substantial increase in the percentage of both mutants to form viable spores (Table 1). An equal mixture of $G_{\alpha} 4^{H C}$ and wild-type cells also results in development similar to that of wild-type cells alone (Fig. 6A,E,F) and an increase in the ability of $G_{\alpha} 4^{H C}$ cells to form spores (Table 1). These results indicate that the rescue of the $G_{\alpha} 4^{H C}$ phenotype, which is presumably due to an increase in expression of the $G_{\alpha} 4$ subunit, is not dependent on cells that lack $G_{\alpha} 4$ gene expression.

\section{Discussion}

The aberrant developmental morphology and extremely low level of spore production observed for $g_{\alpha} 4$ cells indicate that the $G_{\alpha} 4$ gene is essential for proper development and spore production. This developmental require-
Figure 6. Developmental morphology wild-type, $g_{\alpha} 4$, and $G_{\alpha} 4^{H \mathrm{C}}$ chimeras. Wild-type and mutant cells were grown and plated for development as described in Materials and Methods. Cells of a particular strain were either developed as a homogeneous population or mixed with an equal number of cells of another strain. Final morphology of $A$, wild-type cells alone; $B$, wild-type cells mixed with $g_{\alpha} 4$ cells; $C, g_{\alpha} 4$ cells alone; $D, g_{\alpha} 4$ cells mixed with $G_{\alpha} 4^{H C}$ cells; $E, G_{\alpha} 4^{H C}$ cells alone; $F, G_{\alpha} 4^{H C}$ cells mixed with wild-type cells.

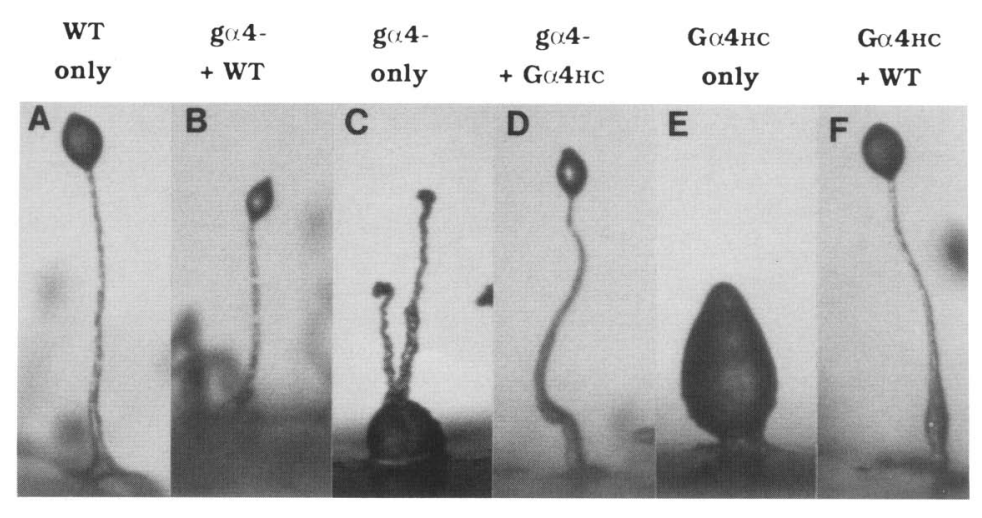




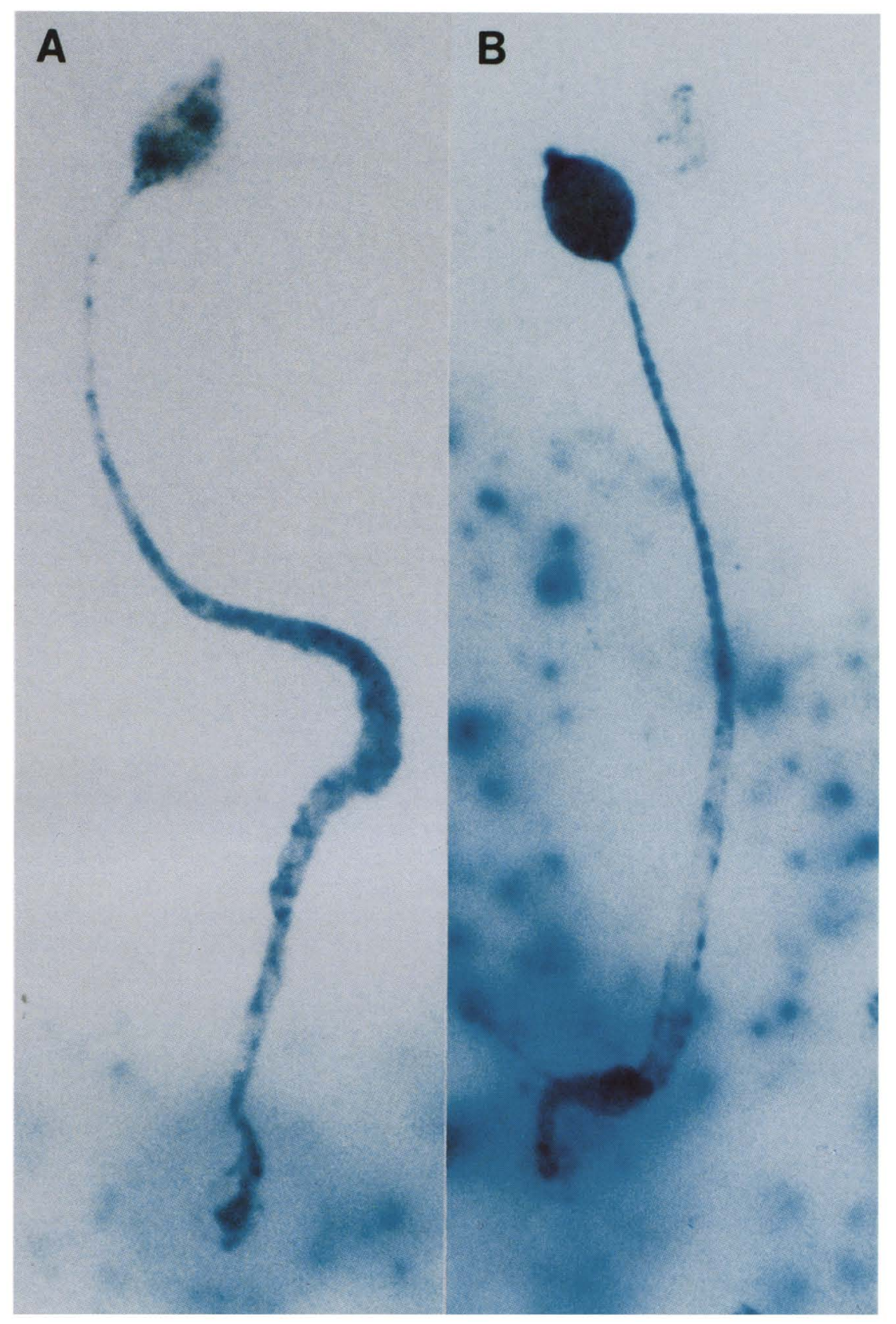

Figure 7. Cytological staining of the $p A C T 6:: 1 a c Z$ construct in $g_{\alpha} 4 \times$ wild-type chimeric fruiting bodies. Development and staining procedure are described in Materials and methods. (A) Clonal $g_{\alpha} 4$ cells carrying the $p A C T 6:: 1 a c Z$ construct mixed with untransformed wild-type cells; $(B)$ clonal wild-type cells carrying the $p A C T 6:: 1 a c Z$ construct mixed with untransformed $g_{\alpha} 4$ cells. ment for $G_{\alpha} 4$ function appears to start as early as the mound stage, based on the slightly reduced induction of the DdrasD and pst-cath/CP2 genes in $g_{\alpha} 4$ cells at this stage of development. This initiation point of $\mathrm{G}_{\alpha} 4$ function is consistent with the substantial increase in $G_{\alpha} 4$ expression in wild-type cells at this developmental stage. Phenotypes observed in $g_{\alpha} 4$ cells at later developmental stages might be directly dependent on $\mathrm{G}_{\alpha} 4$ function at these stages or, perhaps, might be the indirect results of defects resulting from the lack of $G_{\alpha} 4$ function earlier in development. The spatial expression of the $p G_{\alpha} 4: \because 1 a c Z$ gene fusion suggests that only a subset of cells with a distribution similar to anterior-like cells prominently express the $G_{\alpha} 4$ gene; however, it is possible that other cells within the multicellular aggregate also express $G_{\alpha} 4$ at a very low level.

The wild-type morphology and partial rescue of $g_{\alpha} 4$ cell spore production in $g_{\alpha} 4 \times$ wild-type cell chimeras suggest that the $\mathrm{G}_{\alpha} 4$-mediated signal transduction pathway has a non-cell-autonomous function. One possible model for $\mathrm{G}_{\alpha} 4$ function, based on analogies with other $\mathrm{G}_{\alpha}$ subunits, is depicted in Figure 8 . The $\mathrm{G}_{\alpha} 4$ subunit, in conjunction with $\mathrm{G}_{\beta}$ and $\mathrm{G}_{\gamma}$ subunits, is likely to be involved in the transduction of the signal $A$ from a cellsurface receptor $R$ to an intracellular effector $E$. To account for complementation in chimeras, it is possible 
Figure 8. Model of $\mathrm{G}_{\alpha} 4$ subunit function in the production of an intercellular developmental signal (for description of model, see Discussion).

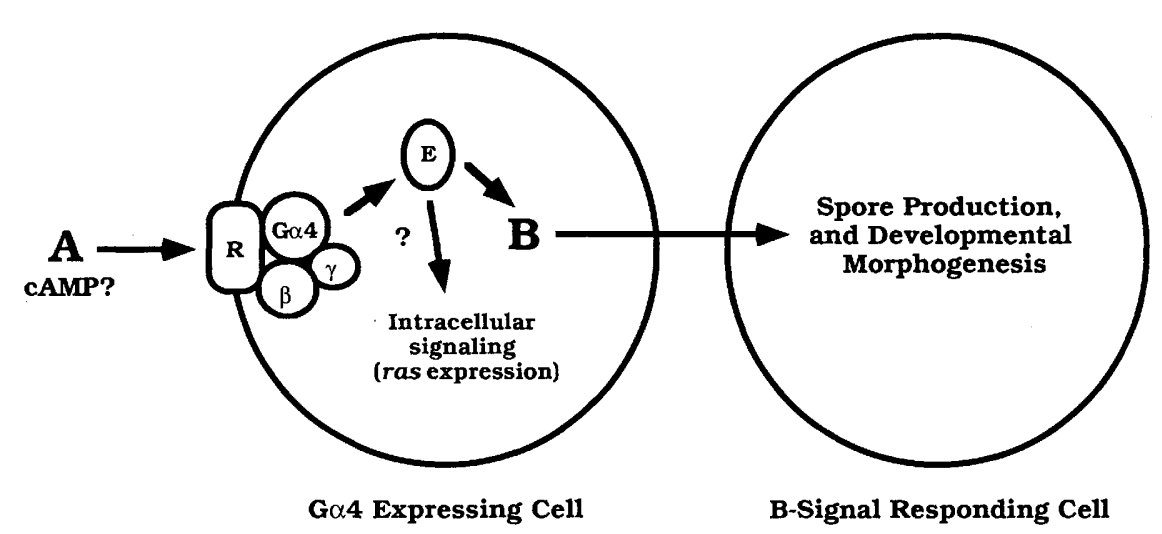

that the $\mathrm{G}_{\alpha} 4$ signal transduction pathway may be directly or indirectly responsible for the production of a second intercellular signal $B$ that promotes proper morphology and spore production in cells that do not necessarily express the $G_{\alpha} 4$ gene. The nature of this second intercellular signal is not known, but it might be mediated by a diffusible extracellular morphogen or, perhaps, by cell-surface factors. Two Dictyostelium morphogens, cAMP and DIF (differentiation-inducing factor), are potential candidates for this signal (see Morris et al. 1987, Williams 1988; Devreotes 1989; Firtel et al. 1989; Kimmel and Firtel 1991; Mann and Firtel 1991). By analogy to most other heterotrimeric $G$ proteins, $R$ in our model is postulated to be a seven-transmembrane domain receptor. Considering that cAMP is known to play an essential role in late development (see Williams 1988; Kimmel and Firtel 1991), it is possible that the cAMP receptors cAR2 and cAR4, which are preferentially expressed in the multicellular stages (Kimmel and Firtel 1991; Saxe et al. 1991a,b/, might couple to the $G_{\alpha} 4$ subunit at these stages. This model is based only on the $g_{\alpha} 4$ null phenotype, and not on the $G_{\alpha} 4^{H C}$ phenotype, because we do not known whether the $G_{\alpha} 4^{H C}$ phenotype is directly related to $\mathrm{G}_{\alpha} 4$ function (see below). Other models for $G_{\alpha} 4$ function are possible, including models in which $\mathrm{G}_{\alpha} 4$ functions completely cell autonomously by regulating morphogenesis. In such a model, wild-type cells in $g_{\alpha} 4 \times$ wild-type chimeras might rescue the $g_{\alpha} 4$ phenotype by carrying or lifting $g_{\alpha} 4$ cells through morphogenesis. The spatial pattern of $G_{\alpha} 4$ expression, based on $p G_{\alpha} 4:: 1 a c Z$ analysis, suggests that $G_{\alpha} 4$ function is limited to only a small subset of cells. Thus, such a "celllifting" model would require that this apparently small population of $\mathrm{G}_{\alpha} 4$-expressing cells physically mediate morphogenesis for the entire organism.

In addition, the $\mathrm{G}_{\alpha} 4$-mediated signal transduction pathway may also function cell autonomously, as suggested by the unequal production of wild-type and $g_{\alpha} 4$ spores in $g_{\alpha} 4 \times$ wild-type chimeras, the reduced expression of the DdrasD gene in shaking cultures of $g_{\alpha} 4$ cells, and the slow plaque growth rate of $g_{\alpha} 4$ cells on bacterial plates. The lower production of $g_{\alpha} 4$ spores in $g_{\alpha} 4 \times$ wildtype chimeras might be due to the inability of $g_{\alpha} 4$ prespore cells to fully differentiate or to $g_{\alpha} 4$ cells being pre- disposed to become stalk cells. The latter of these two possibilities might be explained by a deficiency in $g_{\alpha} 4$ cells during vegetative growth that influences later developmental decisions. Previous reports have suggested that parameters, such as position in the cell cycle at the time of starvation, affect the propensity of a cell to differentiate into either a stalk cell or spore (McDonald and Durston 1984; Weijer et al. 1984; Gomer and Firtel 1987). Although $G_{\alpha} 4$ gene expression is relatively low during vegetative growth, preliminary studies indicate that this expression is detected in $10-20 \%$ of the vegetative cells at any given time (J.A. Hadwiger and R.A. Firtel, unpubl.), which might reflect cell-cycle regulation of expression. These results are very similar to those described for the vegetative expression of the DdrasD gene (Esch and Firtel 1991). The unusually slow growth of $g_{\alpha} 4$ plaques and the unusually fast growth of $G_{\alpha} 4^{H C}$ plaques on bacterial lawns compared with that of wildtype plaques also suggest that $G_{\alpha} 4$ functions during vegetative growth.

Although the molecular basis of the $G_{\alpha} 4^{H C}$ phenotype is not known, it is possible that an inappropriate stoichiometry of the $G_{\alpha} 4$ subunit with $G_{\beta \gamma}$ subunits or other factors (e.g., receptors, effectors, etc.) might result in the premature or extended activation of the $G_{\alpha} 4$ signaling pathway or, perhaps, interfere with signaling pathways mediated through other $G_{\alpha}$ subunits, as has been observed for other G-protein subunits (Cole et al. 1990; Nomoto et al. 1990; Whiteway et al. 1990). The ability of wild-type cells to rescue the deficient spore production in $G_{\alpha} 4^{H C}$ cells suggests that the $G_{\alpha} 4^{H C}$ cells are deficient in an intercellular signal. However, this deficiency is different than that of $g_{\alpha} 4$ cells, because the two mutants can partially complement each other in chimeric organisms.

This analysis of $\mathrm{G}_{\alpha} 4$ function in Dictyostelium development has revealed signal transduction processes that are important during the differentiation of the multicellular state. The deficiency in spore production and morphological phenotypes displayed by $g_{\alpha} 4$ and $G_{\alpha} 4^{H C}$ cells offers strong selection and screening procedures for isolating suppressors of aberrant $\mathrm{G}_{\alpha} 4$ function. Further genetic and biochemical analyses of the signal transduction pathway mediated by the $\mathrm{G}_{\alpha} 4$ subunit are likely to 
increase our overall knowledge of development in Dictyostelium, as well as development in other organisms.

\section{Materials and methods}

\section{Strains and medium}

In this study the following axenic haploid strains were used: KAx-3, JH8 (pyr5-6), JH142 $\left(g_{\alpha} 4:: P Y R 5-6\right), \mathrm{JH} 182\left(G_{\alpha} 4^{H C}\right.$ contains a high copy number of the $G_{\alpha} 4$ expression vector pJH154). The strain $\mathrm{JH} 8$ was constructed from the $\mathrm{KAx}-3$ strain by a site-specific gene disruption of the PYR5-6 gene. More specifically, a SalI linker was ligated to a PVuII site within the open reading frame of the PYR5-6 gene contained on the vector pUCPYR5-6 (Kalpaxis et al. 1990). The resulting pyr5-6 mutant gene was excised with $A s p 718$ and transformed into KAx-3 cells. Transformants were selected in HL5 medium containing 5-FOA and uracil to select for cells that are deficient at the PYR5-6 locus and thus are uracil auxotrophs (Kalpaxis et al. 1990). One of the clonal transformants, designated JH8, contained the SalI site within the PYR5-6 locus as determined by DNA blot analysis, indicating a gene replacement at this locus with the mutant allele (data not shown). The JH8 strain was also used to create another auxotrophic strain, $\mathrm{JH10}$, which contains a disruption of the THY1 locus by insertion of the PYR5-6 gene at the NcoI site within the THY1 open reading frame (Dynes and Firtel 1989). This resulting JH10 strain is an auxotroph for thymidine, similar to the strain HPS400, and can be transformed with a vector containing the THY1 gene, selecting for thymidine prototrophy. All strains used in this study were isogenic to the wild-type strain $\mathrm{KAx}-3$, except at the loci noted, and were grown in HL5 medium or on $K$. aerogenes unless otherwise noted.

Clonal isolates were obtained by plating cells in association with $K$. aerogenes on SM nutrient agar plates. Solitary Dictyostelium amebae feed on the bacteria, resulting in a clonal clearing or plaque in the bacterial lawn. As the plaque gets larger, the cells in the middle of the clone starve and undergo multicellular development. Developmental morphologies can then be viewed with the oldest aggregates closest to the middle of the plaque (for details, see Firtel and Chapman 1990).

\section{DNA constructs}

The $G_{\alpha} 4$ expression vector was created by the insertion of a $4.2-\mathrm{kb}$ genomic fragment containing the $G_{\alpha} 4$ gene into the BamHI site of the phagemid $\mathrm{pT}_{3} \mathrm{~T}_{7} 18 \mathrm{U}$ (Pharmacia LKB) to produce the plasmid pJH56. A 2.2-kb EcoRI-BamHI fragment from the plasmid B10SX (Nellen and Firtel 1985) that contains a pAct $6::$ Neo gene fusion was cloned into the EcoRI site of the plasmid pJH56 to create the plasmid pJH154. The pJH154 plasmid was linearized with the SmaI site within the vector backbone before transforming into cells to increase the probability of random integration.

The $p G_{\alpha} 4::$ lac $Z$ gene fusion vector was created by insertion of a $4.2-\mathrm{kb}$ BamHI-EcoRI fragment containing the lac $Z$ gene-coding region and the $2 \mathrm{H} 3$ transcription termination sequence from pSP60-lacZ plasmid (Haberstroh and Firtel 1990) into the BamHI-EcoRI sites of the plasmid pAT153L, resulting in the plasmid pJH146. This plasmid was digested with BamHI, treated with mung bean nuclease to blunt ends, digested with SphI site, and ligated to a $2.0-\mathrm{kb}$ ClaI /the large fragment of DNA polymerase- $S p h I$ fragment containing the $G_{\alpha} 4$ promoter region to create the plasmid $\mathrm{pJH} 156$. The $2.2-\mathrm{kb}$ EcoRI fragment containing the $p A c t 6:: N e O^{x}$ gene fusion (see above) was inserted into an EcoRI site of pJH156 to create pJH161. The pAct6::Neor gene fusion plasmid was created by insertion of a Sall linker into the HindIII site near the ACT6 promoter on the plasmid pA6PT::lacZ (Dingermann et al. 1989) to create the plasmid pJH73. A SalI-Asp718 fragment that contained the $p A C T 15:: N e O^{r}$ gene fusion from the pnDE $\Delta$ l plasmid (Leiting and Noegel 1988) was inserted into the SalI site of pJH73, after filling in the Asp718 site and adding a Sall linker, to create the plasmid $\mathrm{pJH} 74$.

Analysis of morphology, spore production, and $\beta$-galactosidase activity

Analyses of morphology, spore production, and $\beta$-galactosidase activity were performed on cells grown axenically in shaking cultures of HL5 medium to mid-log phase $\left(1 \times 10^{6}\right.$ to $2 \times 10^{6}$ cells $/ \mathrm{ml}$ l. To examine synchronous morphological differentiation, cells grown axenically were washed free of medium in 12 $\mathrm{mM} \mathrm{Na} / \mathrm{K}$ phosphate buffer ( $\mathrm{pH} 6.1$ ), resuspended in phosphate buffer at $2 \times 10^{7}$ cells, and spread on non-nutrient plates for development. Under these conditions, wild-type cells aggregate between 7 and $9 \mathrm{hr}$, and fruiting bodies are formed in $24-26 \mathrm{hr}$ (for details, see Firtel and Chapman 1990).

For spore analysis and $\beta$-galactosidase staining, cells were spread on nitrocellulose filters, which were then laid on top of non-nutrient agar plates (Haberstroh and Firtel 1990). Spore analysis was conducted by washing cells off of the filters with $10 \mathrm{~mm}$ EDTA $(\mathrm{pH} 6.5$ ) and treating with $0.1 \%$ Nonidet $\mathrm{P}-40$ or with incubation at $42^{\circ} \mathrm{C}$ for $30-60$ min before plating with $K$. aerogenes on nutrient plates. The resulting plaques on the bacterial lawn were scored for morphological phenotype. Histochemical localization of $\beta$-galactosidase activity was determined by using the X-gal staining procedure described by Haberstroh and Firtel (1990).

\section{DNA and RNA blots}

Dictyostelium DNA blots were performed as described by Sambrook et al. (1989), and RNA blots were done as described by Mann and Firtel (1987). DNA probes were generated by random primer probe synthesis using a Prime-a-Gene kit (Promega) according to the manufacturer's instructions. Analysis of gene expression in shaking cultures treated with cAMP was done as described by Mehdy and Firtel (1985).

\section{Acknowledgments}

We thank K. Esch, L. Haberstroh, and J.A. Powell for cell typespecific gene probes and lac $Z$ gene fusions, and $\mathrm{C}$. Gaskins and J.A. Powell for critical reading of the manuscript. We also thank T. Dingermann for providing vectors containing the PYR5-6 gene and the $p A C T 6:: 1 a c Z$ gene fusion and for providing methods for 5-FOA selection in Dictyostelium. J.A.H. was supported by an American Cancer Society postdoctoral fellowship (ACS PF-3285). The work was supported by U.S. Public Health Service grants (GM30693 and GM37830) to R.A.F.

The publication costs of this article were defrayed in part by payment of page charges. This article must therefore be hereby marked "advertisement" in accordance with 18 USC section 1734 solely to indicate this fact.

\section{References}

Bourne, H.R., D.A. Sanders, and F. McCormick. 1991. The GTPase superfamily: Conserved structure and molecular mechanism. Nature 349: 117-127. 
Boy-Marcotte, E., F. Vilaine, J. Camonis, and M. Jacquet. 1984. A DNA sequence from Dictyostelium discoideum complements ura3 and ura5 mutations of Saccharomyces cerevisiae. Mol. Gen. Genet. 193: 406-413.

Cole, G.M., D.E. Stone, and S.I. Reed. 1990. Stoichiometry of G protein subunits affects the Saccharomyces cerevisiae mating pheromone signal transduction pathway. Mol. Cell. Biol. 10: $510-517$.

Datta, S., R.H. Gomer, and R.A. Firtel. 1986. Spatial and temporal regulation of Dictyostelium discoideum. Mol. Cell. Biol. 6: 811-820.

Devreotes, P. 1989. Dictyostelium discoideum: A model system for cell-cell interactions in development. Science 245: 1054-1058.

Dingermann, T., N. Reindl, I. Werner, M. Hildebrandt, W. Nellen, A. Harwood, J.G. Williams, and K. Nerke. 1989. Optimization and in situ detection of Escherichia coli $\beta$-galactosidase gene expression in Dictyostelium discoideum. Gene 85: 353-362.

Dynes, J.L. and R.A. Firtel. 1989. Molecular complementation of a genetic marker in Dictyostelium using a genomic DNA library. Proc. Natl. Acad. Sci. 86: 7966-7970.

Esch, R.K. and R.A. Firtel. 1991. cAMP and cell sorting control the spatial expression of a developmentally essential celltype-specific ras gene in Dictyostelium. Genes \& Dev. 5: 9 21.

Firtel, R.A. and A.L. Chapman. 1990. A role for cAMP-dependent protein kinase in early Dictyostelium development. Genes \& Dev. 4: 18-28.

Firtel, R.A., P.J.M. van Haastert, A.R. Kimmel, and P. Devreotes. 1989. G-protein linked signal transduction pathways in development: Dictyostelium as an experimental system. Cell 58: 235-239.

Franke, J. and R. Kessin. 1977. A defined minimal medium for axenic strains of Dictyostelium. Proc. Natl. Acad. Sci. 74: $2157-2161$.

Gilman, A.G. 1987. G proteins: Transducers of receptor-generated signals. Annu. Rev. Biochem. 56: 615-649.

Gomer, R.H. and R.A. Firtel. 1987. Cell-autonomous determination of cell-type choice in Dictyostelium development by cell-cycle phase. Science 237: 758-762.

Haberstroh, L. and R.A. Firtel. 1990. A spatial gradient of expression of a cAMP-regulated prespore cell-type-specific gene in Dictyostelium. Genes \& Dev. 4: 596-612.

Hadwiger, J.A., T.M. Wilkie, M. Stratmann, and R.A. Firtel. 1991. Identification of Dictyostelium $\mathrm{G}_{\alpha}$ genes expressed during multicellular development. Proc. Natl. Acad. Sci. 88: 8213-8217.

Jermyn, K.A. and J.G. Williams. 1991. An analysis of culmination in Dictyostelium using prestalk and stalk-specific cell autonomous markers. Development 111: 779-787.

Jermyn, K.A., M. Berks, R.R. Kay, and J.G. Williams. 1987. Two distinct classes of prestalk-enriched mRNA sequences in Dictyostelium discoideum. Development 100: 745-755.

Johnson, G.L. and N. Dhanasekaran. 1989. The G-protein family and their interaction with receptors. Endocrine Rev. 10: $317-331$.

Kalpaxis, D., H. Werner, E. Boy-Marcotte, M. Jacquet, and T. Dingermann. 1990. Positive selection for Dictyostelium mutants lacking uridine monophosphate synthase activity based on resistance to 5-fluoro-orotic acid. Dev. Genet. 11: 396-402.

Kesbeke, F., Snaar-Jagalska, B.E., and van Haastert, P.J.M. 1988. Signal transduction in Dictyostelium $f g d A$ mutants with a defective interaction between surface cAMP receptor and a GTP-binding regulatory protein. I. Cell Biol. 197: 521-528.
Kesbeke, F., P.J.M. van Haastert, R.J.W. De Wit, and B.E. SnaarJagalska. 1990. Chemotaxis to cyclic AMP and folic acid is mediated by different $G$ proteins in Dictyostelium discoideum. J. Cell Sci. 96: 669-673.

Kimmel, A.R. and R.A. Firtel. 1991. Signal transduction pathways regulating development of Dictyostelium discoideum. Curr. Opin. Genet. Dev. 1: 383-390.

Kumagai, A., M. Pupillo, R. Gundersen, R. Miake-Lye, P.N. Devreotes, and R.A. Firtel. 1989a. Regulation and function of $\mathrm{G} \alpha$ protein subunits in Dictyostelium. Cell 57: 265-275.

Kumagai, A., S.K.O. Mann, M. Pupillo, G. Pitt, P.N. Devreotes, and R. A. Firtel. 1989b. A molecular analysis of $G$ proteins and control of early gene expression by the cell surface cAMP receptor in Dictyostelium. Cold Spring Harbor Symp. Quant. Biol. 53: 675-685.

Kumagai, A., J. Hadwiger, M. Pupillo, and R.A. Firtel. 1991. Molecular analysis of two $\mathrm{G} \alpha$ protein subunits in Dictyostelium. I. Biol. Chem. 266: 1220-1228.

Leiting, B. and A. Noegel. 1988. Construction of an extrachromosomally replicating transformation vector for Dictyostelium discoideum. Plasmid 20: 241-248.

Loomis, W.F., ed. 1982. The development of Dictyostelium discoideum. Academic Press, New York.

Mann, S.K.O. and R.A. Firtel. 1987. Cyclic AMP regulation of early gene expression in Dictyostelium discoideum: Mediation via the cell surface cyclic AMP receptor. Mol. Cell. Biol. 7: 458-469.

1991. Cell activation: Genetic approaches. In Advanced regulation of cell growth (ed. J. Mond, A. Weiss, and J. Camber, l, vol. II, pp. 9-40, Raven Press, New York.

McDonald, S.A. and A.J. Durston. 1984. The cell cycle and sorting behavior in Dictyostelium discoideum. I. Cell Sci. 66: 195-204.

Mehdy, M.C. and R.A. Firtel. 1985. A secreted factor and cyclic AMP jointly regulate cell-type-specific gene expression in Dictyostelium discoideum. Mol. Cell. Biol. 5: 705-713.

Mehdy, M., D. Ratner, and R.A. Firtel. 1983. Induction and modulation of cell-type-specific gene expression in Dictyostelium. Cell 32: 761-771.

Milne, J.L. and M.B. Coukell. 1991. A Ca ${ }^{+}{ }^{+}$transport system associated with the plasma membrane of Dictyostelium discoideum is activated by different chemoattractant receptors. I. Cell Biol. 112: 103-110.

Morris, H.R., G.W. Taylor, M.S. Masento, K.A. Jermyn, and R.R. Kay. 1987. Chemical structure of the morphogen differentiation inducing factor from Dictyostelium discoideum. $\mathrm{Na}$ ture 328: 811-814.

Neer, E.J. and D.D. Clapham. 1988. Role of G protein subunits in transmembrane signalling. Nature 333: 129-134.

Nellen, W. and R.A. Firtel. 1985. High-copy-number transformants and co-transformation in Dictyostelium. Gene 39: 155-163.

Nomoto, S., N. Nakayama, K. Arai, and K. Matsumoto. 1990. Regulation of the yeast pheromone response pathway by $G$ protein subunits. EMBO J. 9: 691-696.

Pears, C.J., Mahbubani, H.M., and J.G. Williams. 1985. Characterization of two highly diverged but developmentally coregulated cysteine proteinase genes in Dictyostelium discoideum. Nucleic Acids Res. 13: 8853-8866.

Reymond, C.D., R.H. Gomer, M.C. Mehdy, and R. A. Firtel. 1984. Developmental regulation of a Dictyostelium gene encoding a protein homologous to mammalian ras protein. Cell 39: 141-148.

Sambrook, J., E.F. Fritsch, and T. Maniatis. 1989. Molecular cloning: A laboratory manual, 2nd ed. Cold Spring Harbor Laboratory Press, Cold Spring Harbor, New York. 
Saxe, C.L. III and R.A. Firtel. 1986. Analysis of gene expression in rapidly developing mutants of Dictyostelium discoideum. Dev. Biol. 115: 407-411.

Saxe, C.L. III, R.L. Johnson, P.N. Devreotes, and A.R. Kimmel. 1991a. Multiple genes for cell surfacer cAMP receptors in Dictyostelium discoideum. Dev. Genet. 12: 6-13.

. 1991b. Expression of a cAMP receptor gene of Dictyostelium and evidence for a multigene family. Genes \& Dev. 5: 1-8.

Simon M.I., M.P. Strathmann, and N. Gautam. 1991. Diversity of $\mathrm{G}$ proteins in signal transduction. Science 252: 802-808.

Sternfeld, J. and C. David. 1982. Fate and regulation of anteriorlike cells in Dictyostelium slugs. Dev. Biol. 93: 111-118.

Strathmann, M. and M.I. Simon. 1990. G protein diversity: A distinct class of $\alpha$ subunits is present in vertebrates and invertebrates. Proc. Natl. Acad. Sci. 87: 9113-9117.

Strathmann, M., T.M. Wilkie, and M.I. Simon. 1989. Diversity of the G-protein family: Sequences from five additional $\alpha$ subunits in the mouse. Proc. Natl. Acad. Sci. 86: 7407-7409.

Weijer, C.J., G. Duschl, and C.N. David. 1984. Dependence of cell-type proportioning and sorting on cell cycle phase in Dictyostelium discoideum. J. Cell Sci. 70: 133-145.

Whiteway, M., L. Hougan, and D.Y. Thomas. 1990. Overexpresion of the STE4 gene leads to mating response in haploid Saccharomyces cerevisiae. Mol. Cell. Biol. 10: 217-222.

Williams, J.G. 1988. The role of diffusable molecules in regulating the cellular differentiation of Dictyostelium discoideum. Development 103: 1-16.

Williams, J.G., K.T. Duffy, D.P. Lane, S.J. McRobbie, A.J. Harwood, D. Traynor, R.R. Kay, and K.A. Jermyn. 1989. Origins of the prestalk-prespore pattern in Dictyostelium development. Cell 59: 1157-1163. 


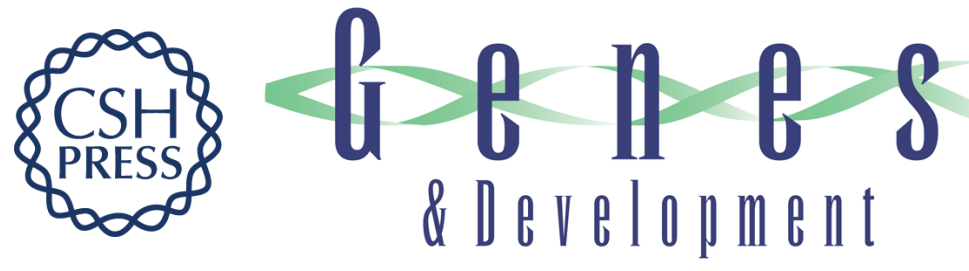

\section{Analysis of G alpha 4, a G-protein subunit required for multicellular development in Dictyostelium.}

$\mathrm{J}$ A Hadwiger and R A Firtel

Genes Dev. 1992, 6:

Access the most recent version at doi:10.1101/gad.6.1.38

References This article cites 48 articles, 22 of which can be accessed free at:

http://genesdev.cshlp.org/content/6/1/38.full.html\#ref-list-1

License

Email Alerting

Service

Receive free email alerts when new articles cite this article - sign up in the box at the top right corner of the article or click here.

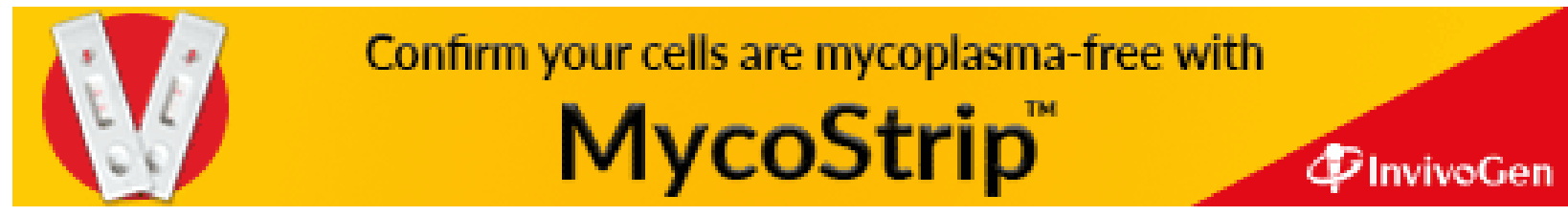

